\title{
Kanser hastalarına yönelik BETTER modeline dayalı cinsel danıșmanlık
}

\author{
Sexual consultancy based on BETTER model for cancer patients
}

Zeynep Ölçer®, Ümran Oskay®

\section{öz}

Kanser ve kanser tedavilerine bağlı olarak ortaya çıkan cinsel sağlık sorunları üzerinde durulması gereken önemli bir konudur. Cinsellik hemşirelik bakımının önemli bir parçası olmasına rağmen, hemşirelerin bu konuyu ele almada güçlük yaşadıkları görülmektedir. BETTER modeli cinsel danışmanlıkta uygun adımlar sunarak hastalara bütüncül bakım verilmesinde onkoloji hemşirelerine yardımcı olabilir. BETTER modeli bazı kelimelerin baş harflerinin bir araya gelmesinden oluşan bir modeldir. Kanser hastalarında BETTER modelinin kullanılmasıla cinsel sağlığın sürdürülmesine katkı sağlanabilir.

Anahtar Kelimeler: BETTER modeli, cinsellik, danışmanlık, hemşirelik, kanser

\section{Gíriș}

Cinsel sağllk kişinin zihinsel, duygusal, sosyal ve entelektüel yönlerinin bir bütünüdür. Cinsellik, cinsel ilişkide bulunmaktan çok daha fazlasını ifade etmektedir. ${ }^{\left[{ }^{[1]}\right.}$ Kanser ve kanser tedavileri nedeniyle meydana gelen cinsel sağlık sorunları üzerinde durulması gereken önemli bir konudur. Hastalar terk edilme, cinsel çekiciliği kaybetme veya yalnız kalma gibi endişeler yaşayabilir; üreme yeteneğini kaybedeceğini yeni kuracağı ilişkilerin yürümeyeceğini, ömrünün az kaldığını düşünebilir. Hastanın eşi/partneri ise eşine zarar vereceğini veya kanserin kendisine bulaşabileğini düşünerek eşinden/partnerinden cinsel açıdan uzaklaşabilir. [2] Özellikle genç hastalarda yaşam kalitesi, beden imgesi bozulur ve sosyal izolasyon görülebilir. ${ }^{[3]}$

'Ankara Medipol Üniversitesi, Sağlık Bilimleri Fakültesi, Hemşirelik Bölümü, Ankara, Türkiye

${ }^{2}$ Istanbul Üniversitesi-Cerrahpaşa, Florence Nightingale Hemşirelik Fakültesi,

Kadın Sağlığı ve Hastalıkları Hemşireliği Bölümü, stanbul, Türkiye

\section{Yazısma Adresi/ Correspondence:}

Dr. Öğr. Üyesi Zeynep Ölçer

Anafartalar Mahallesi Talatpasa Bulvarı, Biga 2 Sokak No: 2 Altındag 06050, Ankara,

Türkiye

Tel. $\quad$ +905442466412

E-mail: zeynepolcer6@gmail.com

Geliș/ Received: $\quad$ 17.11.2019

Kabul/ Accepted: $\quad$ 26.12.2019

\section{ABSTRACT}

Sexual health problems associated with cancer and cancer treatments are important issues to be addressed. Although sexuality is an important part of nursing care, it appears that nurses have difficulty in addressing this issue. The BETTER Model can assist oncology nurses in providing holistic care to patients by offering appropriate steps in sexual counselling. BETTER Model is a model consisting of certain words the capital letters of which come together as an acronym. The use of BETTER model in cancer patients can contribute to the maintenance of sexual health.

Keywords: BETTER model, cancer, consultancy, nursing, sexuality
Onkoloji klinik ve polikliniklerinde zamanın büyük bir bölümünün kanser tedavisi ve semptom yönetimine ayırılması tedavi sürecinde hastaların cinsellikle ilgili endişelerinin belirlenmesi, cinsel sağlıklarının değerlendirilmesi ve danışmanlık hizmeti verilmesi gibi konuların geri plana atılmasına neden olabilmektedir. ${ }^{[4,5]}$ Cinsel sağlık ve cinsellik, palyatif hasta bakımının da önemli bir bileşenidir. Tüm hastaların cinsellikle ilgili konuları klinisyenlerin gündeme getirmesi yönünde beklentileri olduğu, cinselliklerini tartışmayı ve sorgulamayı istedikleri bildirilmektedir. ${ }^{[4,6,7]}$

Hemşireler, kanser hastalarıyla direk olarak iletişime geçen ve onlarla daha fazla zaman geçiren sağlık profesyonelleridir. ${ }^{\left[{ }^{[}\right]} \mathrm{Bu}$ nedenle hemşireler, hastaların cinsel sağlık ve işlevlerinin değerlendirilmesinde, kanserin ve uygulanan tedavilerin sebep olduğu cinsel sorunların belirlenmesinde ve bu sorunlarla başa çıkmada çok uygun pozisyondadır. ${ }^{[4,5]}$ Ancak cinsellik konuları hasta bakım sürecine dahil etmemek veya konuşmaktan kaçınmak hastanın bütüncül olarak değerlendirilmesini engellemektedir. ${ }^{[4]}$

$\mathrm{Bu}$ derlemenin amacı, kanser hastalarına cinsel danışmanlıkta kullanılan BETTER Modeli’ne ilişkin bilgi sağlamaktır. 


\section{Kanserin Cinsel Sağlığa Etkisi}

Kanser ve uygulanan tedavilerin cinsel sağlık üzerine olumsuz etkisi olmaktadır. ${ }^{[1,6,8]}$ Sağlıklı popülasyonda erkeklerin \%31'inde, kadınların da \%43'ünde görülen cinsel işlev bozuklukları prevalansının kanserli kadın hastalarda \%30100 oranlarında, kanserli erkek hastalarda ise $\% 30$ oranında orgazmla ilişkili bozukluklar, \%49 oranında sertleşme bozuklukları görüldüğü bildirilmektedir. ${ }^{[5,9]}$

Doğrudan cinsel organ ile ilgili olmasa bile kanser ve tedavileri, cinsel işlevlerin bozulmasına yol açabilmektedir. ${ }^{[5]}$ Kadınlarda ağrılı cinsel ilişki, lubrikasyonda azalma, orgazma ulaşma yeteneğinde azalma veya duyu kaybına bağlı genital duyarlılıkta değişiklikler görülürken, erkeklerde sertleşme bozuklukları, meninin üretradan atılamaması (anejakülasyon), veya mesaneye boşalması (retrograd ejakülasyon) veya orgazm yetersizliği görülmektedir. ${ }^{[3,5,6,8-10]}$ Tedaviler nedeniyle testislerin etkilenmesine bağlı testosteron düzeyi azalır ve bununla birlikte cinsel işlev bozukluğu yaşanabilir ve yaşam kalitesi etkilenebilir. ${ }^{[5]}$ Cinsel istek kaybı, ilişkiye girme sıklığında azalma ve cinsel olarak çekici hissetmeme her iki cinsiyet için de ortak sorunlardır. $[5,6,8-11]$

Doğrudan ya da dolaylı olarak üreme organlarını etkileyen kanser türleri (serviks, uterus, overler, vajina, prostat, penis, mesane ve rektum) ve tedavileri hormonal, lokal ve mekanik önemli sorunlara yol açar. Bu hastalıkların tedavisinde kullanılan cerrahi yöntemler, kemoterapi ve radyoterapi tedavileri yan etkileri nedeniyle hasta ve partnerlerin cinsel yaşamlarını olumsuz etkiler. Çiftlerde cinsel istek kaybı, memnuniyette azalma, cinselliğe ilginin azalması, orgazm güçlüğ̈̈, uyarılma yetersizliği, ağrılı cinsel ilişki vb. sorunlar ortaya çıkabilir. ${ }^{[7,12]}$ Acquati ve ark., kanser hastalarıyla yaptığı çalışmasında cinsel memnuniyette ve ilişki sıklığında azalma bulmuştur. Kemoterapi alanlarda, kadınlarda ve yaşılıarda cinsel işlev bozukluğunun zamanla arttığı görülmüştür. ${ }^{[3]}$ Wettergren ve ark. çalışmasında kanser tanısının konulmasından sonraki bir yıl cinsel işlev bozukluklarının yaşandığını ve hastaların \%70'inde 2 yıl sonrasında bile olumsuz algıların devam ettiğini belirlemiştir. ${ }^{[0]}$

Cinsellikteki değişiklikler, beklenmeyen kanser tanısına, tümörün lokasyonuna, cinsiyete, yaşa bağlı gelişen cinsel fonksiyonlardaki değişikliklere (erkeklerde erektil bozukluklar, kadınlarda vajinal kuruluk, atrofi, elastikiyet kayb1 vb. menopozal değişiklikler, kanserin tedavisine, doku kaybının derecesine, beden imajındaki değişikliklere, infertiliteye, ağrıya, yorgunluğa ve kişinin eşi/partneri ile olan iletişim sorunlarına, cinselliğe karşı inanç veya tutumlara göre farklılaşabilir. ${ }^{[3,5,8-10]}$
Çiftler, kanser ve tedavileri nedeniyle cinsellik konusunda çelişkili duygular ve ikilemler yaşar. ${ }^{[7]}$ Kanser hastalarında organ ampütasyonu veya stoma olmasına bağlı olumsuz beden imajı, inkontinans ve sızıntı olacağına dair endişeler, kendini daha az çekici hissetme, sosyal ve fiziksel sınıllılık, cinsel ilişki sırasında utanç duyma gibi durumlar görülebilir. ${ }^{[5,12]}$ Eş/ partner ise hastalık ve hastalıkla ilgili sorunlarla baş etmeye çalışı̆ı̆ 1 bir dönemde eşine yönelik cinsel duygular beslemesinden dolayı suçluluk duyabilir. Bu nedenle kişide cinsel istek, uyarılma ve işlev bozuklukları görülebilir. ${ }^{[7]}$ Cinsel sağlık sorunları sadece fiziksel sağlığı etkilemez, aynı zamanda ruh sağlığını, aile sağlığını ve sosyal sağlığı da olumsuz etkiler. ${ }^{[0]}$ Hemşireler kanser hastalarının cinsel sağlık ile ilgili sorun ve kaygıların dile getirilmesinde anahtar konumdadır. Kanser hastalarının cinsel işlevlerini etkileyen faktörlerin belirlenmesi ve bu sorunlarla baş etmede danışmanlık ve rehberlik konusunda hemşirelerin önemli görevleri vardır. ${ }^{[1]}$

\section{Kanser Hastalarına Cinsel Sağlık Danıșmanlığı}

Cinselliğe yönelik konuların rahatça konuşulamaması ve toplumda tabu olarak değerlendirilmesi hastaların cinsellikle ilgili yeterli bilgilendirilmemesine neden olmaktadır. ${ }^{[13]}$ Yu ve Sherman yaptığı çalışmada hastaların cinsellikle ilgili konularda konuşmaktan çekindiklerini bulmuştur. ${ }^{[14]}$ McCallum ve ark. da benzer şekilde çoğu kadın için cinsellikle ilgili konuların tabu olduğunu ve bu konudaki endişelerini sağlık personeli ile tartışmaya utandıklarını belirlemiştir. Aynı zamanda kadınlar, onkoloji hekimlerinin cinsel sağlığa daha az önem verdiklerini ve hastalığın tedavisi, tekrarlama belirtileri vb. medikal konulara daha fazla odaklandıklarını düşündüklerini belirtmiştir. ${ }^{[15]}$ Southard ve Keller hastaların cinselliğin gündeme getirilmesi ve onlara sorulmasını istediklerini ancak hemşirelerin çok az sayıda hastanın cinsel sorunlarını ele aldığını saptamıştı. ${ }^{[16]}$

Sağlık profesyonellerinin cinsel danışmanlık konusunda yapacakları desteğin önemi büyüktür. Cinselliğin bir tabu olduğu ülkemizde hemşireler, hastalar ifade etmese bile cinsellikle ilgili problemleri belirleyip uygun girişimlerle bu problemlerle baş etmesine yardımcı olabilirler. ${ }^{[17,18]}$ Cinsellik hemşirelik bakımının önemli bir yere sahiptir ancak hemşirelerin uygulamada bu konuyu ele almada güçlük yaşadıkları görülmektedir. ${ }^{[1]}$ Hastaların çeşitli sebeplerle cinsel sorunlara yönelik bilgilendirilmediği, yaşadıkları güçlükler ile baş etmede yeterince desteklenmediği görülmektedir. ${ }^{[1,13]}$

Pınar çalışmasında hemşirelerin cinsel danışmanlıkta bulunma oranını \%26,2 olarak bulmuştur. Hemşirelerin çoğu hastalarının cinsel sorun yaşadıklarını düşünmesine 
rağmen ancak çok az sayıda hastanın bu konuda kendilerinden danışmanlık istediğini ve çalıştıkları kurumda cinsel danışmanlığın yeterince yapılmadığını belirtmişlerdir. ${ }^{[1]}$ Oysa kanserli hastalar için hemşirelerin önemli bir sosyal destek kaynağı olduğu bilinmektedir. ${ }^{[13]}$ Cinsel sağlığı korumak cinsel işlev zarar görmüş olsa da bu zararı en aza indirmeye çalışmak, tedavi sonrası yeni duruma uyumunu kolaylaştırmak için cinselliği ifade etme ve haz alma yeteneğini geliştirmek, alternatif yöntemler konusunda hastayı bilgilendirmek ve rehberlik etmek gerekmektedir. ${ }^{[9]}$ Cinsel danışmanlık hemşirelik bakımına entegre edilmeli, cinsel işlevi değerlendirmek ve klinik ortamda kapsamlı yönetim sağlamak için rutin protokoller geliştirilmelidir. ${ }^{[1,10]}$

Hemşireler, kanser hastalarının cinsel sağlığını uygun cinsel soru formları kullanarak değerlendirmesi, hemşirelik girişimlerini planlayabilmesi ve danışmanlık yapabilmesi için cinsellikle ilgili konularda bilgi sahibi olmalı ve etkili iletişim becerilerini kullanarak konuşabilmelidir. Cinsel değerlendirme ve cinsel danışmanlık konusunda geliştirilen modelleri kullanmak hemşirelere kolaylık sağlayabilir. ${ }^{\left[{ }^{[}\right.}$

Kanser ve kanser tedavilerinin cinsel sağlık üzerindeki etkileri iki düzeyde değerlendirilir. ${ }^{[9]}$

Birinci düzey değerlendirmede hastalığa ve uygulanan tedavilere ilişkin ortaya çıkan sorunlar belirlenir; tüm hemşireler tarafından kolaylıkla yapılabilir. ${ }^{[9]}$ Cinselliği değerlendirmeye, önce cinsel öykü alarak başlanılmalıdır. Hastanın genel sağlık durumu, hastalık öncesi ve şu anki cinsel yaşa$\mathrm{m}$, hastalık ve cinsellikle ilgili inanışları, cinselliğe ilişkin tutumu değerlendirilmelidir. ${ }^{[5]}$

İkinci düzey değerlendirmede birinci düzey değerlendirmede tespit edilen cinsel sorun üzerine odaklanılır. Tespit edilen sorun çözülemezse veya bu sorun danışmanlık yapan kişinin yetkisini aşarsa, bu konuda eğitim almış bir terapiste başvurulmalıdır. Günümüzde pek çok sağlık profesyoneli, cinsellikle ilgili sorunları belirlemede ve bu sorunları tartışmada modellerden yaralanmaktadır. ${ }^{[9]}$

Hemşirelik modelleri, birey ve ailesinden verilerin sistemli ve kapsamlı bir biçimde toplanmasını sağlamaya, toplanan verilere bakış açısı getirmeye ve çözüm önerileri geliştirmeye, uygun girişimler planlayıp değerlendirme yapmaya yaramaktadır. Model kullanımı, hemşirelik bilgisinin ve uygulamalarının sistematik olmasını ve hasta ile profesyonel bir iletişim kurulmasını sağlar. ${ }^{[19-26]}$

Hemşireler hastalarla daha uzun zaman geçirip doğrudan ilişki kurarak eğitim ve danışmanlık hizmeti vermektedir. Cinsellik hemşirelik bakımının önemli bir parçası olmasına rağmen, hemşirelerin cinselliği ele almada güçlük yaşadıkları görülmektedir. Sağlık personeli ile hastalar arasındaki iletişim için etkin dinleme, sessizliği kullanma, soru sorma, yansitma, özetleme vb. teknikleri kullanabileceği gibi modelleri de kullanabilir. Modeller cinsel danışmanlıkta uygun adımlar sunarak hastalara bütüncül bakım vermeye yardımcı olur. ${ }^{[26-28]}$ Cinsel istek ve davranışlarla ilgili bilgileri genel bakımla birleştiren bir model, hemşirelerin cinsel bilgiler hakkında bilgi edinmelerine ve değerlendirmelerine yardımcı olabilir. ${ }^{\left[{ }^{[]}\right.}$

Cinsel konularla ilgili danışmanlıkta en zor kısım görüşmenin başlatılmasıdır. Sağlık profesyonellerinin cinsel sağlık danışmanlığında kullandıkları modeller görüşmenin başlatılmasına yardımcı olmaktadır. ${ }^{[27-31]}$ Cinsel danışmanlık yapılırken "Kaplan Modeli","PLISSIT Modeli", "ALARM Modeli", "Schover Modeli", "ALLOW Modeli" ve "BETTER Modeli" gibi modellerden yararlanılmaktadır. ${ }^{[5,7-9,28]}$ Özellikle kanser hastaları için geliştirilen "BETTER Modeli” cinselliğin değerlendirilmesinde ve yönetiminde yardımcı olabilecek bir modeldir. ${ }^{[5,7,8,11]}$

\section{BETTER Modeli}

"BETTER Modeli" cinselliğin değerlendirilmesinde bakım standartlarının sağlanması, bütüncül bir bakım verilmesinde onkoloji hemşirelerine yardımcı olabilir. Böylece cinsel sorunlarla ilgili eğitim planlaması, uygulanması ve danışmanlık yapılması ile cinsel sağlı̆̆ın korunması ve geliştirilmesine katkı sağlanacaktır. ${ }^{[27-31]}$ Ölçer ve Oskay meme kanserli hastalara "BETTER Modeli'ni" kullarak cinsel sağlık eğitimi verdikleri çalışmada kadınların kayganlaşma, orgazm, ağrı ve cinsel sağlık ile ilgili ölçek puanlarının iyileştiğini ve beden imajı puanlarının arttığını belirlemiştir. ${ }^{[32]}$

"BETTER Modeli" bazı kelimelerin baş harflerinden oluşmuş bir modeldir. ${ }^{[28-31]}$

\section{"Konuyu gündeme getirmek (Bringing up the topic)":} Kanserli hastaların cinsel gereksinimlerini veya sorunlar1nı konuşabilmek için öncelikle mahremiyeti sağlanmalı, sakin, izole ve rahat bir ortam oluşturmalıdır. Bu aşamada hastalarla tanışılır, görüşmeler hakkında bilgi verilir ve cinsellikle ilgili konuşulabileceği belirtilir. ${ }^{[5,7,16,27-29,33-35]}$ Örneğin: "Prostat kanseri ve tedavilerinden sonra çiftlerin olast cinsel sorunlarla ilgili sorular olmaktadır. Eğer sizin de sorularnnz varsa, tereddüt etmeden sorabilirsiniz." sseklinde ifadelerle hasta cesaretlendirilmelidir. ${ }^{[5]}$ Değerlendirme yapılırken hasta ile cinselliğin anlamı ve endişeler konusunda konuşulma firsatı yaratılır. Tartışmaya, eğer hasta istiyorsa hastanın eşi/partneri de dahil edilmeli ya da onunla ayrıca konuşulmalıdır. Hastanın ve eşinin/partnerinin değişen durumlarla yüzleşmesine yardım edilmelidir. ${ }^{[16,27-29,33-35]}$ 
Hemşireler danışmanlık verirken güvene dayalı iletişim kurarlarsa daha başarılı olabilirler. ${ }^{[4,7]}$ Hemşire, uygun iletişim tekniklerini kullanmalı, hasta ve eşinin/partnerinin güvenini kazanmalı ve onların cinsellikle ilgili aklından geçenleri açığa çıkarmalı ve onları rahatlatmalıdır. ${ }^{[7]}$ Görüşme, güven sağlamak amacıyla sosyal ilişki tarzında yürütülmelidir. Görüşmelerde paylaşılanların özel olduğunu ve bu nedenle gizli kalacağını açıklamak yararlıdır. ${ }^{[16,27-29,33-35]}$

Bakıma ilişkin roller yerine getirilirken her hasta ve ailesinin özgün olduğu göz önünde bulundurulmalıdır. ${ }^{[7]}$ Cinsel yaşamda, hastalık ve tedavinin olduğu kadar hastanın dini ve kültürel inançlarının da etkisinin olduğu, hastaların farklı yönelimleri olabileceği gerçeği göz ardı edilmemeli ve bireylerin farklı değerlere sahip olduğunun bilincinde olunmalıdır. ${ }^{[7,16,27-29,33,34]}$

“Cinselliğin hayatın önemli bir parçası olduğunu açıklamak (Explain you are concerned with quality-of-life issues, including sexuality)": Bu yöntemle cinsellikle ilgili konuları tartışmak normalleşir ve hastanın sıkılması veya yalnız hissetmesi engellenir. Etkili bir danışmanlık için, cinsel sorunları tartışmaya başlamadan önce amacın ne olduğu açıklanmalıdır. Hastaya cinselliğin yaşamın önemli bir parçası olduğu söylenmelidir. ${ }^{[5,16,27-29,33-35]}$ Örneğin; "Şu anda aklinizdaki son şey cinsellik olabilir ama iyileştikçe hayatın bu yönüne ilgi duymaya başladiğınızı göreceksiniz.'[5] Hastalığın cinsellik de dâhil bireyin yaşamının tüm boyutları üzerine olan etkilerinin ele alınacağı belirtilmelidir. $[5,16,27-29,33-35]$

Palyatif bakım hastalarında cinsellik, hassas bir konudur. Amaç hasta ve eşi/partnerinin yaşam kalitesini yükseltmek olmalıdır. Palyatif bakım gerektiren hastalar, kendi bedenlerindeki değişiklikler nedeniyle eşleri/partnerleri tarafından cinsel olarak arzulanmadıkları endişesi taşıyabilir; böyle bir kaygı, eşler arasındaki ilişkiyi zedeleyebileceği gibi cinsel işlevleri de bozabilir. ${ }^{[]]}$Dostça ve uygun iletişim teknikleri kullanılmalıdır. Tedavilerin cinsel yaşam ve beden imajı üzerine etkilerine ilişkin kaygılarını ifade etmelerine izin verilmeli, cinsellik hakkında soru sormaları için hastalar teşvik edilmelidir. ${ }^{[5,16,27-29,33-35]}$

Normal olan cinsellik tanımlamalı, cinsel sorunlar hakkında hasta bilgilendirilmelidir. Hastanın var olan cinsel yaşamı değerlendirilmelidir. Hastalık ve tedavilerden sonra cinsel yaşamında olan değişiklikleri ifade etmesi ve bu değişimlerin özel yaşamındaki etkilerini anlatması için hasta cesaretlendirilmelidir. Hastanın eşiyle/partneriyle ilişkileri gözden geçirilerek, hastaya yakın ilişkilerini geliştirmesi yönünde destek verilmelidir. Tüm sorulara cevap vermek mümkün olmayabilir ancak hastanın endişeleri ile ilgili konuşulmak istendiği belirtilmelidir. ${ }^{[5,16,27-29,33-35]}$
"Hastalara kaygıları ile ilgili yeni kaynaklar bulacağını söyleme (Telling patients that resources will be found to adres their concerns)": Hastalara cinsel işlev bozukluğu olabileceği ve sorunun çözümüne yönelik destek sağlanacağı açıklanmalıdır. ${ }^{[5,16,27-29,33-35]}$ Cinsellikle ilgili kaygıların şiddeti belirlenmelidir. Hastanın her ortamda yaşadığı sorunları ifade etmesine izin verilmelidir. Hastalıkla ilgili yaşanan duygu ve düşünceleri ifade etmek, aynı sorunları yaşayan duygu ve düşünceleri paylaşmak, sosyal aktiviteleri devam ettirmek hastalığın tedavisinde yararlıdır. Hastanın baş etme yöntemleri değerlendirilmeli ve etkili baş etme yöntemleri tartışılmalıdır. Hastanın etkili baş etme yöntemlerini kullanması sorunların çözümüne ve benlik saygısının arttırılmasına yardımcı olur. Hastalığın ve tedavilerin hastanın cinsel yaşamı üzerindeki etkisi tartışılmalıdır. Hasta ve eşinin/partnerinin, cinsel sorunlarla baş etmede destek kaynaklarını belirlemesine yardım edilmeli ve sorunun giderilmesinde kullanabilecekleri kaynaklar konusunda bilgilendirilmelidir. Hasta ve eşini/partnerini bilgilendirmek için cinsellikle ilgili materyaller verilmeli, cinsel işlevi artıracak tıbbi ve psikososyal girişimler hasta ve yakınlarına tanıtılmalıdır. ${ }^{[16,27,29,33-35]}$ Hemşire hasta ve eşine/ partnerine yardım edebilmek için bu konuda donanımlı olmalı, planlanan hemşirelik girişimlerine ve kullanılan yöntemlere rağmen danışmanlık sonunda cinsel sorunlar çözümlenemezse hastanın konu ile ilgili özelleşmiş bir uzmana sevk edilmesini sağlamalıdır. ${ }^{[4,7]}$ Örneğin; "Cinsel ilişki sırasinda ă̆rı sorununu neden yaşadiğınızdan emin değilim. Bu sorununuzu doktorunuza ileteceğim. ’[5]

"Görüşmenin zamanlanması (Timing of intervention)": Hastaya görüşmelerde ele alınacak konular ve görüşmelerin amacı hakkında açıklama yapılır. Zaman hasta için uygun olmayabilir, istediği herhangi bir zamanda bilgi talep edebileceği söylenir. ${ }^{[5,27,28,33]}$ Örneğin; "Endometrium kanseri ve tedavileri sonrası cinsel sorunlarla ilgili bazı kitap, dergi, broșür ve videolarımı olduğunu bilmenizi isterim. Burada iletişsime geçebileceğiniz merkezlerin adres ve telefon numaraları bulunuyor. ${ }^{\{[5]}$

Hastalar için öncelikli konu hayatta kalmaktır ancak cinsel sorunlarla ilgili gelecekte konuşmaya istekli olunduğu belirtilmelidir. Her görüşmede cinselliğin ele alınma zamanı önemlidir. ${ }^{[27,28,33]}$ Uygun bilgilerin zamanında verilmesiyle, cinsel sağlığa yönelik iyi sonuçlar sağlanabilir ve hasta memnuniyeti arttırılabilir. ${ }^{[13]}$ Hastanın görüşmelerden beklentileri ve gereksinimleri hakkında konuşulmalı, her zaman soru sorabileceği konusunda cesaretlendirilmelidir. Hastanın beklentileri ve gereksinimlerine göre görüşmelerde ele alınacak konular ve bunların öncelikleri ile görüşmelere ayrılacak sürelerde değişiklik yapılabilir. ${ }^{[27,28,33]}$ 
“Tedavinin yan etkileri konusunda eğitim (Educate patients about the side effects of their cancer treatments)": Hastayı kanser ve tedavilerinin yan etkileriyle bilgilendirmek kadar, cinsellik üzerine olan yan etkileri hakkında bilgilendirmek de önemlidir. ${ }^{[5,16,27-29,33,34]}$ Hastayla hastalık, tedaviler ve stres nedeniyle cinsel yaşamın değişebileceği hakkında konuşulmalıdır. Bu konudaki duyarlılığı dikkate alınarak, fiziksel değişimlerle ilgili duygularını ifade etmesi için hasta cesaretlendirilmelidir. [16,27-29,33,34] Örneğin; "Bazı kadınlar histerektomi ameliyatından sonra orgazm duygusunun farklı olduğunu bildirmektedir. Siz bunu yaşamayabilirsiniz, ama bu durumun olabileceğini bilmenizi isterim. '[5]

Cinsellikle ilgili semptomlar ve bunların yönetimi ile ilgili hastanın bilgisi değerlendirilmelidir. Kanser tedavisinin yaşamını nasıl etkileyeceği konusunda eğitim yapılmalıdır. Hastalara danışmanlık tarzında emosyonel destek verilmelidir. ${ }^{[16,27-29,33,34]}$ Palyatif bakım hastalarında, hasta ve eşinin/partnerinin sevgilerini ifade etmelerine firsat verilmeli ve cinsel sağlık gereksinimleri dikkate alınmalıdır. Hemşire, terminal dönem hasta ve eşi/partnerine, çift olarak ilişkilerini değerlendirebilme ve semptomların kendileri için ne anlam ifade ettiğini anlama fırsatını vermeli ve cinsel yaşamlarını sürdürebilmeleri için destek olmalıdır. ${ }^{[7]}$

Hemşire, hastanın kendine ilişkin duyguları, düşünceleri, kendisini nasıl gördüğ̈̈ konusunda duygularını ifade etmesi için cesaretlendirmelidir. Hasta ile güvenli iletişim başlatmalı ve hasta istediği sürece bu güvenli iletişimi sürdürmelidir. Hastanın gelecekle ilgili gerçekçi beklentiler içerisinde olmasına ve planlar oluşturmasına destek olmalıdır. Hastayı, güçlü yönlerini fark etmesi ve bu durumla mücadelede kendine özgü başa çıkma yolları geliştirmesi yönünde desteklemelidir. ${ }^{[16,27-29,33,34]}$

Hasta ve eşinin/partnerinin öğrenmek istedikleri konulara ve gereksinimlerine öncelik verilmeli; sorulara açı ve samimi cevaplar verilmelidir. ${ }^{[16,27-29,33,34]}$

"Kaydetme (Recording)": Yapılan tüm değerlendirmeler ve girişimler kayıt edilmelidir. ${ }^{[5,16,27-29]}$ Örneğin; "Hastayla cerrahi sonrası olabilecek cinsel yan etkiler tartşıldd. Hastaya konu ile ilgili bilgi alabileceği merkezin iletişim bilgileri ile okuma materyali verildi. ${ }^{[5]}$ Kayıtlarda da mahremiyet ve gizliliğin sağlanması önemlidir. ${ }^{[7]}$

\section{SONUÇ}

Cinsel sağlıkla ilgili danışmanlıkta en zor kısım görüşmenin başlatılmasıdır. Sağlık profesyonellerinin kullandıkları modeller görüşmenin başlatılmasına yardımcı olmaktadır.
BETTER Modeli onkoloji hemşireleri için geliştirilmiş bir model olması sebebiyle, cinsel danışmanlıkta uygun adımlar sunarak hastalara bütüncül bakım verilmesi, cinsel sorunlarla ilgili eğitim planlanması ve uygulanması, gerektiğinde hastaların danışmanlık hizmetlerine yönlendirilmesi için kullanılabilir. Böylece cinsel sağlığın korunması ve geliştirilmesine katkı sağlanacaktır.

\section{Hakem Değerlendirmesi}

Dış bağımsız

Çıkar Çatışması

Yazarlar çıkar ilişkisi olmadığını beyan etmişlerdir.

Finansal Destek

Herhangi bir mali destek alınmamıştır.

\section{Peer-review}

Externally peer-reviewed.

Conflict of Interest

No conflict of interest was declared by the authors.

Financial Disclosure

No financial support has been received.

\section{KAYNAKLAR}

1. Pınar G. Kanser tedavisi alan hastalarda cinsel disfonksiyon ve danışmanlığa ilişkin hemşirelik yaklaşımları. Gülhane Tıp Derg 2010;52:241-7. https://arastirmax.com/tr/system/files/ dergiler/9678/makaleler/52/4/arastirmax-kanser-tedavisi-alanhastalarda-cinsel-disfonksiyon-danismanliga-iliskin-hemsirelikyaklasimlari.pdf

2. Yılmaz SD, Bal MD, Beji NK. Jinekolojik kanser tedavilerinin kadın cinsel yaşamına etkisi ve hemşirelik yaklaşımı. Androloji Bült 2010;40:75-7.

3. Acquati C, Zebrack BJ, Faul AC, Embry L, Aguilar C, Block R, et al. Sexual functioning among young adult cancer patients: a 2-year longitudinal study. Cancer 2018;124:398-405. [CrossRef]

4. Terzioğlu F, Alan H. Jinekolojik kanser tedavisi sırasında yaşanan psikolojik sorunların kadının cinsel yaşamına etkisi. Anadolu Hemşirelik ve Sağlık Bilimleri Derg 2015;18:140-7. [CrossRef]

5. Aygin D, Yaman Ö. Kanserli hastalarda cinsellik nasıl değerlendirilmeli? Androloji Bült 2017;19:98-107. [CrossRef]

6. Leung MW, Goldfarb S, Dizon DS. Communication about sexuality in advanced illness aligns with a palliative care approach to patient-centered care. Curr Oncol Rep 2016;18:1-6. [CrossRef]

7. Coşkun A, Özerdoğan N. Palyatif bakımda cinsel sağlık. ACU Sağlık Bilimleri Derg 2018;9:371-7. [CrossRef]

8. Faghani S, Ghaffari F. Effects of sexual rehabilitation using the PLISSIT model on quality of sexual life and sexual functioning in post-mastectomy breast cancer survivors. Asian Pac J Cancer Prev 2016;17:4845-51. [CrossRef]

9. Dinçer Y, Oskay Ü. Kanser ve cinsellik. Androloji Bült 2015;17:311-4. https://www.journalagent.com/androloji/pdfs/ AND_17_63_311_314.pdf

10. Wettergren L, Kent EE, Mitchell SA, Zebrack B, Lynch CF, Rubenstein $\mathrm{MB}$, et al. Cancer negatively impacts on sexual function in adolescents and young adults: the AYA HOPE study. Psychooncology 2017;26:1632-9. [CrossRef]

11. Saboula NE, Shahin MA. Effectiveness of application of plissit counseling model on sexuality for breast cancer's women undergoing treatment. Am J Nurs Sci 2015;4:218-30. [CrossRef] 
12. Benedict C, Philip EJ, Baser RE, Carter J, Schuler TA, Jandorf L, et al. Body image and sexual function in women after treatment for anal and rectal cancer. Psycho-Oncology 2016;25:316-23. [CrossRef]

13. Serçekuş P, Türkcü SG. Jinekolojik kanserli hastalarda cinsellik. DEUHFED 2015;8:36-8. https://dergipark.org.tr/tr/download/ article-file/753264

14. Yu Y, Sherman KA. Communication avoidance, coping and psychological distress of women with breast cancer. J Behav Med 2015;38:565-77. [CrossRef]

15. McCallum M, Lefebvre M, Jolicoeur L, Maheu C, Lebel S. Sexual health and gynecological cancer: conceptualizing patient needs and overcoming barriers to seeking and accessing services. J Psychosom Obstet Gynecol 2012;33:135-42. [CrossRef]

16. Southard NZ, Keller J. The importance of assessing sexuality: a patient perspective. Clinical J Oncol Nurs 2009;13:213-7. [CrossRef]

17. Kedde H, van de Wiel HBM, Weijmar Schultz WCM, Wijsen C. Meme kanserli genç kadınlarda sübjektif cinsel iyilik ve cinsel davranış (Çev. Aygin D, Uzun E). Supp Care Cancer 2013;21:1993-2005. [CrossRef]

18. Pehlivan S, Yıldırım Y, Fadıloğlu Ç. Kanser, kültür ve hemşirelik. Acıbadem Üniversitesi Sağlık Bilimleri Derg 2013;4:168-74. http://acibadem.dergisi.org/uploads/pdf/pdf_AUD_205.pdf

19. Velioğlu P. Hemşirelikte Kavram ve Kuramlar. İstanbul: Alaş Ofset; 1999. s.372-99.

20. Fawcett J. Contemporary Nursing Knowledge Analysis and Evoulation of Nursing Models and Theories, 2nd ed. Philadelphia: Fa Davis Company; 2005. p.364-437.

21. Alligood MR, Tomey AM. Nursing Theory: Ultilization \& Application, 3rd ed. US: Mosby Company; 2006. p.307-33.

22. Ay F, Ertem Ü, Özcan N, Ören B, Işık R, Sarvan S. Temel Hemşirelik Kavramlar, İlkeler, Uygulamalar, 2. Baskı. İstanbul: İstanbul Medikal Yayıncllı; 2008. s.5-6.

23. Birol L. Hemşirelik Süreci, 7. Baskı. İzmir: Bozkaya Matbacılık; 2007. s.78-82.

24. Gigliott E. The value of nursing models in practice. Dokuz Eylül Üniversitesi Hemşirelik Yüksekokulu Elektronik Derg 2008;1:4250 .
25. Kacaroğlu Vicdan A. Hemşirelik bakımında model kullanımına bir örnek: modifiye radikal mastektomi olmuş bir bayanın, Roy'un adaptasyon modeline göre incelenmesi. Maltepe Üniversitesi Hemşirelik Bilim ve Sanatı Derg 2010;2:106-18. https://docplayer. biz.tr/23855150-Hemsirelik-bakiminda-model-kullanimina-birornek-modifiye-radikal-mastektomi-olmus-bir-bayanin-roy-unadaptasyon-modeline-gore-incelenmesi.html

26. Ursavaş FE, Karayurt Ö, İşeri Ö. Meme kanseri nedeniyle meme koruyucu cerrahi yapılan bir hastaya roy uyum modeline temellendirilmiş hemşirelik yaklaşımı. Eur J Breast Health 2014;10:134-40. [CrossRef]

27. Mick J, Hughes M, Cohen MZ. Using the better model to assess sexuality. Clin J Oncol Nurs 2004;8:84-6. [CrossRef]

28. Açıkgöz F. Cinsel sağlığa yönelik hemşirelik yaklaşım modelleri. Androloji Bült 2011;47:305-307.

29. Katz A. The sounds of silence: sexuality information for cancer patients. J Clin Oncol 2005;23:238-41. [CrossRef]

30. Hordern A. Intimacy and sexuality after cancer. Cancer Nurs 2008;31:E9-17. [CrossRef]

31. Oskay UY, Beji NK, Bal MD, Yılmaz SD. Evaluation of sexual function in patients with gynecologic cancer and evidence-based nursing interventions. Sex Disabil 2011:29:33-41. [CrossRef]

32. Ölçer ZÖ, Oskay Ü. Meme Kanseri Hastalarının Cinsel Sorunlarına Yönelik BETTER Modeline Göre Verilen Eğitimin Etkisi. İstanbul Üniversitesi-Cerrahpaşa Lisansüstü Eğitim Enstitüsü Kadın Sağlığı ve Hastalıkları Hemşireliği Anabilim Dalı, Doktora Tezi, İstanbul; 2019.

33. Çam O, Babacan Gümüş A. Meme kanserli kadınlar için duygusal destek odaklı hemşirelik girişimleri. Cumhuriyet Üniversitesi Hemşirelik Yüksekokulu Derg 2006;10:52-60. http://eskidergi. cumhuriyet.edu.tr/makale/1481.pdf

34. Akyolcu N. Meme kanserinde cerrahi girişim sonrası cinsel yaşam. Meme Sağllğı Derg 2008;4:77-83. http://www. thejournalofbreasthealth.com/content/files/sayilar/12/ buyuk/1151.pdf

35. Uğur Ö. Kanser hastasının semptom yönetimi. Türk Onkoloji Derg 2014;29:125-35. [CrossRef] 